\title{
Electrochemiluminescence immunosensor for highly sensitive detection of 8-hydroxy-2'-deoxyguanosine based on carbon quantum dot coated $\mathrm{Au} / \mathrm{SiO}_{2}$ core-shell nanoparticles
}

\author{
Ting-Ting Zhang, Hui-Min Zhao ${ }^{*}$, Xin-Fei Fan, Shuo Chen, Xie Quan
}

Key Laboratory of Industrial Ecology and Environmental Engineering (Ministry of Education, Dalian 116024, China), School of Environmental Science and Technology, Dalian University of Technology, Dalian 116024, China

Corresponding author: zhaohuim@dlut.edu.cn

\begin{abstract}
An electrochemiluminescence (ECL) immunosensor using Pt electrode modified with carbon quantum dot (CQDs) coated $\mathrm{Au} / \mathrm{SiO}_{2}$ core-shell nanoparticles was proposed for sensitive detection of 8-hydroxy-2'-deoxyguanosine (8-OHdG) in this work. Rabbit anti-8-OHdG antibody was covalently bound to CQDs on the surface of $\mathrm{Au} / \mathrm{SiO}_{2}$ core-shell nanoparticles. Through signal amplification of $\mathrm{Au} / \mathrm{SiO}_{2}$ core-shell nanoparticles, 8-fold enhancement of the ECL signals was achieved. Under optimal conditions, a good linear range from 0.2 to $200 \mathrm{ng} \mathrm{mL}^{-1}$ with a low detection limit of $0.085 \mathrm{ng} \mathrm{mL} \mathrm{m}^{-1}(\mathrm{~S} / \mathrm{N}=3)$ for $8-\mathrm{OHdG}$ detection was obtained. Interfering substances tests showed that the corresponding ECL intensity ( $\triangle \mathrm{ECL}$ ) of $8-\mathrm{OHdG}$ is 8 to 18 times higher than that of guanine, uric acid (UA) and ascorbic acid, demonstrating its good selectivity for 8-OHdG detection. The ECL immnuosensor exhibits long-term stability with a relative standard deviation (RSD) of $8.5 \%$ even after 16 cycles of continuous potential scans. The result of analytical detection of $8-\mathrm{OHdG}$ in real samples was satisfactory. The proposed ECL immnuosensor shows good performance with high sensitivity, specificity, repeatability, stability and provided a powerful tool for $8-\mathrm{OHdG}$ monitoring in clinical samples.
\end{abstract}

Keyword: Core-shell nanoparticle , 8-hydroxy-2'-deoxyguanosine ,

Electrochemiluminescence immnuosensor, Carbon quantum dot

\section{Introduction}


Reactive oxygen species, such as superoxide radical, singlet oxygen, hydroxyl radicals, superoxide anion and peroxyl, are considered as harmful species due to their effect on oxidative DNA damage [1,2]. 8-hydroxy-2'-deoxyguanosine (8-OHdG, also known as 8-oxo-7, 8-dihydroguanine and 8-oxo-dGuo) (Scheme 1), one of the main products of oxidative DNA damage, can mispair with adenine, leading to $\mathrm{G}: \mathrm{C} \rightarrow \mathrm{T}: \mathrm{A}$ transverse mutation [3]. Many researches show that $8-\mathrm{OHdG}$ has a much closer relationship with some disease, such as cancer, diabetes and neurological disorders [4-6]. Therefore, $8-\mathrm{OHdG}$ is concerned as the most investigated biomarker of oxidative DNA damage [7].

Traditional methods for 8-OHdG determination, such as high performance liquid chromatography with electrochemical detection [8], liquid chromatography combined with electrospray ionization tandem mass spectrometry multiple reaction monitoring [9], high performance liquid chromatography/positive electrospray ionization tandem mass spectrometry [10], enzyme-linked immuno sorbent assay [11] and ${ }^{32} \mathrm{P}$-labeling [12], are pretreatment complex, specialized skills required and unavailable for in-situ detection. Electrochemistry sensors are widely applied in detecting various pollutants due to its rapid and high sensitivity $[13,14]$. It also been developed for $8-\mathrm{OHdG}$ detection. For example, electrochemical method based on poly(3-methylthiophene) (P3MT) and polyethylenimine dispersed carbon nanotubes modified glassy carbon electrode (GCE) used as working electrode allowed the sensitive determination of 8-OHdG. But the results of electrochemistry methods above were likely to be affected by other biomolecules or matrix effects $[15,16]$. Fluorescent sensor is another method for 8-OHdG detection which developed in recent years. Qian Zhang et al. [2] reported a DNA aptamer fluorescent sensor for $8-\mathrm{OHdG}$ determination using two triple-stranded DNAs as the scaffolds, which shows inherently insufficient binding constants between aptamers and 8-OHdG due to the small molecule of 8-OHdG.

Electrochemiluminescence (ECL) is a special kind of chemiluminescence (CL) with its light emission preceded by electrochemical reactions [17]. The ECL method presents widespread prospect due to its high sensitivity and good controllability 
compared to the conventional electrochemical and CL technique [18]. Its performance mainly depends on the favourable luminescent characterization of ECL materials. Recently, as a new group of ECL luminophores, quantum dots (QDs) attracted more and more attention [19-21], since they not only exhibit excellent ECL activities but also have the merit of easy labeling. However, reports on QD-based ECL assay for 8-OHdG detection are relatively scarce since the inherently toxicity and low ECL intensity due to the poor stability of conventional QDs used in ECL at high electrochemical potentials [22]. Therefore, nontoxicity and reproducibility are urgently needed for the development of QD-based ECL sensors in 8-OHdG monitoring.

Carbon quantum dots (CQDs), a newly emerging ECL luminophores, have several significant advantages over the previously reported QDs, such as high stability, low toxicity, easy labeling and good biocompatibility [23-25]. To the best of our knowledge, the research report of CQD-based ECL 8-OHdG is hampered by the low ECL intensity of CQDs and the difficulty in reuse of CQDs in an aqueous system [26,27]. Thus, how to effectively amplify ECL signal and solve the reusability simultaneously is the key point in designing a CQDs-based ECL for 8-OHdG detection.

A structure of "core-shell" based on concentric multilayer semiconductor nanoparticles has recently attracted great attention in sensor field due to its large surface-to-volume ratio for modifying QDs. Nanguo Liu et al. [28] reported a well-defined hybrid structures that comprised a gold core coated with a silica shell $\left(\mathrm{Au} / \mathrm{SiO}_{2}\right)$, followed by the modification of CdSe-QDs $\left(\mathrm{Au} / \mathrm{SiO}{ }_{2} / \mathrm{CdSe}-\mathrm{QD}\right)$. The research on the photoluminescence intensities of CdSe-QD and the $\mathrm{Au} / \mathrm{SiO}_{2} / \mathrm{CdSe}-\mathrm{QD}$ nanoparticles prove that the $\mathrm{Au} / \mathrm{SiO}_{2}$ core-shell nanoparticles exhibit excellent ability of signal amplification on photoluminescence. Moreover, due to its robust chemical stability, uniformity and biocompatibility of the $\mathrm{SiO}_{2}$ shell coating, and ease of surface functionalization, we consider $\mathrm{Au} / \mathrm{SiO}_{2}$ core-shell can be used as suitable platform for CQDs immobilization to improve its ECL signal and 
reusability.

Herein, an advanced ECL immunosensor based on the hybrid of CQDs and $\mathrm{Au} / \mathrm{SiO}_{2}$ was fabricated for the supersensitive, rapid, and selective detection of 8-OHdG upon the amplification of CQD ECL signal by $\mathrm{Au} / \mathrm{SiO}_{2}$ core-shell. In the sensor $\mathrm{Au} / \mathrm{SiO}_{2}$ core-shell nanoparticles serve as the platform for CQDs immobilization, which can not only enhance the detection sensitivity but also achieve good recycle of the sensor through avoiding the loss of CQDs. Meanwhile the rabbit anti-8-OHdG antibody serves as the immunosorbent of antigen 8-OHdG. Compared to the previously reported methods, this approach provides a promising tool for the routine detection of $8-\mathrm{OHdG}$.

\section{Experimental}

\subsection{Reagents and chemicals}

8-OHdG (CAS: 88847-89-6), ethyl-3-(dimethyl aminopropyl) carbodiimide (EDC) and N-hydroxysuccinimide (NHS) were purchased from Sigma (America). Rabbit anti-8-OHdG (Ab) was obtained from Beijing Biosynthesis Biotechnology Co., Ltd. (Beijing, China). $\mathrm{HAuCl}_{4} \cdot 3 \mathrm{H}_{2} \mathrm{O}$ (99\%), tetraethoxysilane (TEOS), poly(vinylpyrrolidone) (PVP) and trisodium citrate (99\%) were bought from Xilong Chemical Co., Ltd. (Guangdong, China). $\mathrm{NH}_{4} \mathrm{OH}$ was purchased from Tianjin Fuyu Fine Chemical Co., Ltd. (Tianjin, China). Uric acid (UA) was purchased from Tokyo Chemical Industry Co., Ltd. (Japan). Guanine and (3-Aminopropyl) trimethoxysilane (APS) were supplied by J\&K Scientific Ltd. (Beijing, China). Bovine serum albumin (BSA) was purchased from Beijing Aoboxing Bio-tech Co., Ltd. (Beijing, China). Ascorbic acid, $\mathrm{K}_{2} \mathrm{~S}_{2} \mathrm{O}_{8}$ (potassium persulfate) and $\mathrm{KCl}$ were bought from Tianjin Bodi Chemical Co., Ltd. (Tianjin, China). Phosphate buffer solution (PBS, 0.1 mol L ${ }^{-1}$, $\mathrm{pH}=7.4)$ was prepared by mixing the stock solutions of $\mathrm{Na}_{2} \mathrm{HPO}_{4}\left(0.1 \mathrm{~mol} \mathrm{~L}^{-1}\right)$ and $\mathrm{NaH}_{2} \mathrm{PO}_{4}\left(0.1 \mathrm{~mol} \mathrm{~L}^{-1}\right)$. Tris-EDTA (TE) buffer was used as dilution solvent of 8-OHdG. Ultrapure water purified by a Millipore water system (resistivity $>18.0 \mathrm{M} \Omega$ $\mathrm{cm}^{-1}$, Laikie Instrument Co., Ltd., Shanghai, China) was used throughout the experiments. 


\subsection{Apparatus}

The ECL emission was detected by a MPI-B multi-parameter chemiluminescence analysis test system (Xi'an Remax Analysis Instrument Co., Ltd., Xi'an, China) with a three electrode system consisting of a bare or modified Pt electrode ( $1 \mathrm{~mm}$-diameter) as the working electrode, the standard calomel electrode ( $\mathrm{SCE}$, saturated $\mathrm{KCl}$ ) and a $\mathrm{Pt}$ wire were used as the reference electrode and the auxiliary electrode, respectively. Electrochemical impedance spectroscopy (EIS) was performed on a CHI 660 electrochemical analyzer (Shanghai Chenhua Instrument, Shanghai, China). Unless noted, the photomultiplier tube (PMT) was $600 \mathrm{~V}$. The morphology of the samples was observed by transmission electron microscopy (TEM) (FEI Tecnai G2 20, America) and scanning electron microscopy (SEM) (Hitachi S-4800) equipped with an X-ray energy dispersive spectroscopy (EDS) (Japan). Photoluminescence (PL) spectra were obtained on a Hitachi F-4500 fluorescence spectrometer (Japan). UV-visible spectra were carried out on a Jasco V-550

spectrometer (Japan). Sonications were carried out on a KQ5200B-type ultrasonic cleaner with the cleaning slot size 300*240*150 mm (Kun Shan Ultrasonic Instruments Co., Ltd., Jiangsu, China).

\subsection{Synthesis of $\mathrm{Au} / \mathrm{SiO}_{2} / \mathrm{CQDs}$ core-shell nanoparticles}

Preparation of CQDs: Ascorbic acid was used as carbon source of CQDs. The mixed liquor of ascorbic acid and ethanol was heated at $180{ }^{\circ} \mathrm{C}$ for $4 \mathrm{~h}$ in a Teflon ${ }^{\circledR}-$ lined stainless steel autoclave and then cooled to room temperature. The dark brown solution was obtained, followed by extracting with dichloromethane. Then a yellow aqueous solution containing CQDs was obtained. The specific processes refer to previous literature [29].

Preparation of $\mathrm{Au}$ nanoparticles (AuNPs): The AuNPs core was synthesized through the seeded growth synthesis process according to literature [30]. Briefly, 2.2 mmol L ${ }^{-1}$ sodium citrate solution $(150 \mathrm{~mL})$ was added into a $250 \mathrm{~mL}$ round-bottomed flask. The solution was heated reflux under vigorous stirring. When the solution start boiling, $1 \mathrm{~mL}$ of $\mathrm{HAuCl}_{4}\left(25 \mathrm{mmol} \mathrm{L}^{-1}\right)$ was injected and kept boiling for 10 minutes. 
Then cooled the mixtures to $90{ }^{\circ} \mathrm{C} .1 \mathrm{~mL}$ of sodium citrate $\left(60 \mathrm{mmol} \mathrm{L}^{-1}\right)$ and $1 \mathrm{~mL}$ of $\mathrm{HAuCl}_{4}$ solution $\left(25 \mathrm{mmol} \mathrm{L}{ }^{-1}\right)$ were sequentially injected, then kept reacting for 30 min at $90{ }^{\circ} \mathrm{C}$. After repeating this process steps (sequential addition of $25 \mathrm{mmol} \mathrm{L}^{-1}$ $\mathrm{HAuCl}_{4}(1 \mathrm{~mL})$ and $60 \mathrm{mmol} \mathrm{L}{ }^{-1}$ sodium citrate $(1 \mathrm{~mL}) 5$ times, a vinicolor aqueous solution containing AuNPs was finally obtained.

Preparation of $\mathrm{Au} / \mathrm{SiO}_{2}$ core-shell nanoparticles: The $\mathrm{Au} / \mathrm{SiO}_{2}$ core-shell nanoparticles were synthesized by Stöber processin accordance to literature [31]. An aqueous solution of poly(vinylpyrrolidone) (PVP, $1 \mathrm{~mL}, 12.6 \mathrm{mgmL}^{-1}$ ) was added to the $180 \mathrm{~mL}$ aqueous solution of as-prepared AuNPs. Subsequently, the mixture stood for $48 \mathrm{~h}$ under magnetic stirring at room temperature, assuring the attachment of PVP molecules on the surfaces of AuNPs. The PVP attached AuNPs were then separated from solution by centrifuging at 12,000 rpm for $30 \mathrm{~min}$ and re-dispersed in $15 \mathrm{~mL}$ of ultrapure water. Thereafter, transfer $5.0 \mathrm{~mL}$ of PVP-modified AuNPs into a beaker containing a total volume of $15 \mathrm{~mL}$ mixture of ammonia $(0.4 \mathrm{~mL})$ and ethanol (14.6 $\mathrm{mL})$ under magnetic stirring. The mixture composed of TEOS $(0.1 \mathrm{~mL})$ and ethanol $(9.9 \mathrm{~mL})$ were injected into the beaker within a period of $6 \mathrm{~h}$. Then stirring reaction was kept for 12 hours. The synthesized $\mathrm{Au} / \mathrm{SiO}_{2}$ core-shell nanoparticles were washed and centrifuged for two times by ethanol and ultrapure water in turn.

Formation of $\mathrm{Au} / \mathrm{SiO}_{2} / \mathrm{CQDs}$ core-shell nanoparticles: The synthesis process (shown in Scheme 2) was carried out according to previous literature [28]. The as-prepared $\mathrm{Au} / \mathrm{SiO}_{2}$ nanoparticles were dispersed in ethanol $(20.0 \mathrm{~mL}) .2 \mu \mathrm{L}$ of APS was added to the solution to modify the silica surface with amine groups. After that the mixture was magnetic stirred for $24 \mathrm{~h}$ at room temperature. The amine-functionalized $\mathrm{Au} / \mathrm{SiO}_{2}$ core-shell nanoparticles were collected by centrifugation and washed twice with ethanol. The as-prepared nanoparticles were re-dispersed in $20.0 \mathrm{~mL}$ of ethanol. Before immobilized on the amine-functionalized $\mathrm{Au} / \mathrm{SiO}_{2}$ nanoparticles, the hydroxyl groups on the surface of CQDs were coverting into carboxyl by adding $0.005 \mathrm{~g}$ of $\mathrm{NaOH}$ and $0.01 \mathrm{~g}$ of $\mathrm{ClCH}_{2} \mathrm{COOH}$ (chloroacetic acid) into $2 \mathrm{~mL}$ of CQDs solution and bath sonicating for $3 \mathrm{~h}$ (frequency: $40 \mathrm{KHZ}$, 
power: $200 \mathrm{~W}$ ) [32]. Then the mixture was added into ethanol solution of amine-functionalized $\mathrm{Au} / \mathrm{SiO}_{2}$ core-shell nanoparticles, and kept magnetic stirring for $12 \mathrm{~h}$ at room temperature. CQDs were self-assembled onto $\mathrm{Au} / \mathrm{SiO}_{2}$ nanoparticle surface due to the strong binding interaction between the $-\mathrm{NH}_{2}$ and the $-\mathrm{COOH}$ of the CQDs. Finally, the hybrid $\mathrm{Au} / \mathrm{SiO}_{2} / \mathrm{CQDs}$ nanoparticles were collected by centrifugation and washed twice with ethanol and ultrapure water in turn.

\subsection{Preparation of the ECL immunosensor}

Prior to modification, the Pt electrode (1 mm-diameter) was mildly polished with $0.5 \mu \mathrm{m}$ and $50 \mathrm{~nm}$ alumina slurry and then washed ultrasonically in ultrapure water and ethanol for a few minutes, respectively. $2 \mu \mathrm{L}$ of the $\mathrm{Au} / \mathrm{SiO}_{2} / \mathrm{CQDs}$ nanoparticles suspension was dropped on the pretreated $\mathrm{Pt}$ electrode (noted as $\mathrm{Pt} / \mathrm{Au} / \mathrm{SiO}_{2} / \mathrm{CQDs}$ ) and then naturally dried at room temperature. The $\mathrm{Pt} / \mathrm{Au} / \mathrm{SiO}_{2} / \mathrm{CQDs}$ electrode was carefully immersed in a solution containing $0.01 \mathrm{~mol}$

$\mathrm{L}^{-1} \mathrm{EDC}$ and $0.025 \mathrm{~mol} \mathrm{~L}^{-1} \mathrm{NHS}$ at least $12 \mathrm{~h}$ for activation. $2 \mu \mathrm{L}$ of $10 \mu \mathrm{g} \mathrm{mL} \mathrm{L}^{-1} \mathrm{Ab}$ was dropped on the electrode surface and kept for at least $12 \mathrm{~h}$ at $4{ }^{\circ} \mathrm{C}$ (noted as $\left.\mathrm{Pt} / \mathrm{Au} / \mathrm{SiO}_{2} / \mathrm{CQDs} / \mathrm{Ab}\right)$. Then, $2 \mu \mathrm{L}$ of $1 \% \mathrm{BSA}$ was dropped on the electrode surface and kept for $3 \mathrm{~h}$ to block the nonspecific sites (noted as $\mathrm{Pt} / \mathrm{Au} / \mathrm{SiO}_{2} / \mathrm{CQDs} / \mathrm{Ab} / \mathrm{BSA}$ ). Finally, the ECL immunosensor was obtained (the whole procedure was presented in Scheme 3). Notably, after every step, the electrode was rinsed with $0.01 \mathrm{~mol} \mathrm{~L}^{-1} \mathrm{PBS}$ $(\mathrm{pH} 7.4)$.

\subsection{Immunoassay of 8-OHdG}

The detection procedures of $8-\mathrm{OHdG}$ are presented in Scheme 4. In summary, the modified electrode was immersed in the incubation solution containing various concentration of $8-\mathrm{OHdG}$ for $10 \mathrm{~h}$ and this process was performed at $37{ }^{\circ} \mathrm{C}$ isothermally in the incubator. After that the modified electrode was rinsed with 0.01 mol L ${ }^{-1}$ PBS (pH 7.4) thoroughly. The modified electrode above was scanned in 0.1 mol L ${ }^{-1}$ PBS ( $\mathrm{pH} 7.4$ ) containing $0.1 \mathrm{~mol} \mathrm{~L}^{-1} \mathrm{KCl}$ and $0.05 \mathrm{~mol} \mathrm{~L}^{-1} \mathrm{~K}_{2} \mathrm{~S}_{2} \mathrm{O}_{8}$. The voltage of PMT was maintained at $600 \mathrm{~V}$ and the potential range was from $-0.2 \mathrm{~V}$ to $-1.0 \mathrm{~V}$ with a scan rate of $0.01 \mathrm{~V} \mathrm{~s}^{-1}$. 


\section{Results and discussions}

\subsection{Characterization of CQDs}

To evaluate the photoluminescence properties of CQDs the photoluminescence spectra and UV/Vis absorption were obtained on the fluorescence spectrometer and the spectrometer (Fig. 1). The photoluminescence intensities of CQDs were obvious under the excitation with different wavelength (a: $300 \mathrm{~nm}-\mathrm{g}: 420 \mathrm{~nm}$ ). The photoluminescence spectra were shifted to longer wavelengths with the increase of excitation wavelength. An optical absorption was obtained in UV region. These results are almost consistent with the data reported in previous literature [33]. It indicates that the photoluminescence intensity of CQDs was satisfied for the ECL immunosensor.

\subsection{Characterization of $\mathrm{Au} / \mathrm{SiO}_{2} / \mathrm{CQDs}$ core-shell nanoparticles}

TEM was used to investigate the morphologies of $\mathrm{Au} / \mathrm{SiO}_{2} / \mathrm{CQDs}$ core-shell nanoparticles. Fig. 2A shows TEM image of $\mathrm{Au} / \mathrm{SiO}_{2} / \mathrm{CQDs}$ core-shell nanoparticles. The diameters of AuNPs were found in the range of $20 \mathrm{~nm}$ to $30 \mathrm{~nm}$, and the silica-shell thicknesses were between $25 \mathrm{~nm}$ and $30 \mathrm{~nm}$. The AuNPs and the $\mathrm{Au} / \mathrm{SiO}_{2} / \mathrm{CQDs}$ core-shell nanoparticles were nearly spherical and apparently well-dispersed. To further verify the successful synthesis of $\mathrm{Au} / \mathrm{SiO}_{2} / \mathrm{CQD}$ s core-shell nanoparticles, EDS was used to investigate the elementary composition of $\mathrm{Au} / \mathrm{SiO}_{2} / \mathrm{CQDs}$ core-shell nanoparticles. It was clearly that $\mathrm{Au}, \mathrm{Si}, \mathrm{O}$, and $\mathrm{C}$ were the elementary components of $\mathrm{Au} / \mathrm{SiO}_{2} / \mathrm{CQDs}$ core-shell nanoparticles (Fig. 2B), and the atomic ratios of them were $15.33 \%, 27.79 \%, 25.41 \%$ and $15.33 \%$, respectively (table 1). The EDS results from different regions were similar, which confirmed that the composition of the obtained materials were uniform.

\subsection{ECL behaviors of the ECL immunosensor}

The ECL behaviors of the immunosensor were recorded in $0.1 \mathrm{~mol} \mathrm{~L}^{-1} \mathrm{PBS}(\mathrm{pH}$ 7.4) containing $0.1 \mathrm{~mol} \mathrm{~L}^{-1} \mathrm{KCl}$ and $0.05 \mathrm{~mol} \mathrm{~L}^{-1} \mathrm{~K}_{2} \mathrm{~S}_{2} \mathrm{O}_{8}$, and ECL electrodes were scanned from -0.2 to $-1.0 \mathrm{~V}$ (Fig. 3). The ECL signal of Pt electrode was very weak (curve a). After the modification with CQDs, the ECL intensity increased. It was 
noted that the ECL intensity of $\mathrm{Au} / \mathrm{SiO}_{2} / \mathrm{CQDs}$ nanoparticles modified electrode (curve f) was about 8 times as high as that of the CQDs modified electrode (curve b), which illustrates that the $\mathrm{Au} / \mathrm{SiO}_{2}$ nanoparticles have an excellent ability of signal amplification. A smaller ECL intensity (curve c) than that of in curve $f$ was observed for $\mathrm{Pt} / \mathrm{Au} / \mathrm{SiO}_{2} / \mathrm{CQDs} / \mathrm{Ab}$, indicating that $\mathrm{Ab}$ has been immobilized on the surface of electrode. After the electrode was encapsulated with BSA (curve d), the successive decline of ECL intensity was detected. Mainly depending on antibody and BSA as proteins were electron inert and they could partially hinder the electron transfer on the surface of working electrode [34]. The ECL intensity further decreased after the electrode was incubated with $8-\mathrm{OHdG}$ sample $\left(100 \mathrm{ng} \mathrm{mL}^{-1}\right)$ (curve e). It indicates that $8-\mathrm{OHdG}$ was specifically bound to antibody, in the meantime the electron transfer on the surface of working electrode was hindered by $8-\mathrm{OHdG}$. Therefore the electrode modified by $\mathrm{Au} / \mathrm{SiO}_{2} / \mathrm{CQDs} / \mathrm{Ab} / \mathrm{BSA}$ could be used for the detection of 8-OHdG.

\subsection{Optimization parameters}

Highly acidic or alkaline surroundings could reduce the biological activity of the protein [35] and further affect the ECL signal of ECL immunosensor. To achieve an optimal ECL signal, $\mathrm{pH}$ value of electrolyte solution 8-OHdG was investigated. As shown in Fig. 4A, a maximum value of the ECL intensity achieved when the $\mathrm{pH}$ value of electrolyte solution was adjusted to $\mathrm{pH}$ 7.4. Hence neutral surroundings at $\mathrm{pH} 7.4$ was selected and used for test throughout this study. The incubation time was another effect factor of the ECL signal, thus different incubation times of 8-OHdG were studied in this part. Fig. 4B shows the effect of incubation time of 8-OHdG on ECL emission. The ECL emission was decreased with incubation time from 4 to $10 \mathrm{~h}$, and a relatively stable value was obtained when the incubation time of 8-OHdG up to10 h. Therefore, $10 \mathrm{~h}$ of the incubation time was chosen for subsequent experiments.

\subsection{ECL detection of 8-OHdG}

Under the optimal conditions, the linear response range and the detection limit of the 8 -OHdG sensing system were measured as follows. The working electrode after 
incubating with a group of $8-\mathrm{OHdG}$ concentrations $(0,0.2,0.5,1,5,10,25,50,100$, 150 and $200 \mathrm{ng} \mathrm{mL}^{-1}$ ) were investigated to evaluate the sensitivity of the ECL immunosensor. With the increase of concentration, the ECL response was reduced (Fig. 5A). The ECL intensity reduced linearly with the concentration of 8-OHdG in the range of 0.2 to $200 \mathrm{ng} \mathrm{mL}^{-1}$ (Fig. 5B). The regression equation is $\triangle \mathrm{ECL}=171.688$ $+249.011 \mathrm{x}$, with a correlation coefficient $\left(\mathrm{R}^{2}\right)$ of 0.937 . The limit of detection (LOD) was $0.085 \mathrm{ng} \mathrm{mL}^{-1}(\mathrm{~S} / \mathrm{N}=3)$. The low LOD might be attributed to the excellent ability of signal amplification with the $\mathrm{Au} / \mathrm{SiO}_{2}$ core-shell nanoparticles, and it is satisfactory to detect the concentration of $8-\mathrm{OHdG}$ in some human biomatrices (the concentration of $8-\mathrm{OHdG}$ in human urine, seminal plasma and breast milk were 2.3-9.3, 0.444-1.047 and 0.178-0.339 $\mathrm{ng} \mathrm{mL} \mathrm{m}^{-1}$, respectively, these data were mentioned in previous literature [36]). Although the LOD of the ECL immunosensor might not satisfy the ranges of all the biological samples, it has a relatively large linear range and a low detection limit compared to previous methods (Table 2).

\subsection{Specificity, reproducibility, stability and feasibility}

For many $8-\mathrm{OHdG}$ detection methods, false positive or errors caused by interferents which co-exist with $8-\mathrm{OHdG}$ in human body or excretion inhibited the accurate detection of $8-\mathrm{OHdG}$. To examine the specificity of the fabricated immunosensor, interferences study was performed using guanine, UA, and ascorbic acid, which were co-exist with 8-OHdG. Here, the interfering substances mentioned above with three concentration levels (100 $\mathrm{ng} \mathrm{mL}^{-1}, 1000 \mathrm{ng} \mathrm{mL}^{-1}$ and $\left.10000 \mathrm{ng} \mathrm{mL}^{-1}\right)$ were detected. By comparison the response signals of the interferents with 8-OHdG in $100 \mathrm{ng} \mathrm{mL} \mathrm{m}^{-1}$, the $\triangle \mathrm{ECL}$ of the interferents is only $5.5 \%-12.5 \%$ of that of $8-\mathrm{OHdG}$ (Fig. 6). The result indicated that these interfering substances have little impact on the detection of $8-\mathrm{OHdG}$, even their concentrations were 100 times higher than that of 8-OHdG.

The reproducibility and operational stability were the major concerns for practical application of immunosensors. The reproducibility of the ECL immunosensor was investigated by prepared five electrodes for the detection $100 \mathrm{ng}$ 
$\mathrm{mL}^{-1}$ of $8-\mathrm{OHdG}$. The relative standard deviation (RSD) of this measurement was $6.8 \%$. The experimental results demonstrated acceptable reproducibility of the ECL immunosensor. Fig. 7 displays the ECL emission of the ECL immunosensor under 16 cycles of continuous potential scans between -0.2 and $-1.0 \mathrm{~V}$ (vs SCE) in $0.1 \mathrm{~mol} \mathrm{~L}^{-1}$ PBS (pH7.4) at $0.01 \mathrm{~V} \mathrm{~s}^{-1}$ for the detection of $100 \mathrm{ng} \mathrm{mL}^{-1}$ of 8-OHdG. A stable ECL signal was observed with the RSD of $8.5 \%$. The life time of the immunosensor was also investigated in 30-day period. The modified electrode was stored in the refrigerator at $4{ }^{\circ} \mathrm{C}$ and measured every 10 days. During the first 10 days, the response current decreased by $1.3 \%$ of its initial response. In the next 10 days and the last 10 days it decreased by $3.7 \%$ and $6.5 \%$, respectively, and maintained more than $93.5 \%$ of the initial response after storing for 30 days. It shows that the stability of the immunosensor was excellent and the life time of the immunosensor could be reach 30 days.

To monitor the feasibility of the developed ECL immunosensor in real samples analyses, the immunosensor was further applied in analyzing the concentrations of 8-OHdG in milk. Recovery experiments were carried out by the standard addition method. The results showed that the recovery ranges from $102.0 \%$ to $110.0 \%$, and that the corresponding RSD ranges from $4.9 \%$ to $7.7 \%$ (Table 3 ). Therefore, the ECL immunosensor could be satisfactorily applied to the detection of $8-\mathrm{OHdG}$ in real samples.

\section{Conclusions}

In this work, we developed an ECL immunosensor based on $\mathrm{Au} / \mathrm{SiO}_{2} / \mathrm{CQDs}$ core-shell nanoparticles for detection of 8-OHdG. ECL emission signal of CQDs increased greatly by using $\mathrm{Au} / \mathrm{SiO}_{2}$ core-shell nanoparticles as the substrate material. With the amplification of ECL signal, the ECL immunosensor displayed a highly sensitive ECL detection with specific immunoreactions. Under optimal conditions, the proposed immunosensor for 8-OHdG exhibited a low detection limit $\left(0.085 \mathrm{ng} \mathrm{mL}^{-1}\right)$ and a wide linear range $\left(0.2-200 \mathrm{ng} \mathrm{mL}^{-1}\right)$. Moreover, this method was successfully applied to the detection of $8-\mathrm{OHdG}$ in real samples. Given the excellent selectivity of 
the ECL immunosensor coupled with acceptable repeatability and stability, this ECL immunosensor could be promising for clinical detection of 8-OHdG. It is expected that to improve the application of CQDs in biological detection by synthesizing CQDs coated $\mathrm{Au} / \mathrm{SiO}_{2}$ core-shell nanoparticles.

\section{Acknowledgement}

This work was supported by the Research Project of Chinese Ministry of Education (No113017A) and National Natural Science Foundation of China (NSFC-JST 21261140334). Thanks Program for Changjiang Scholars and Innovative Research Team in University (IRT_13R05).

\section{References}

[1] I.F.F. Benzie, Evolution of antioxidant defence mechanisms, Eur J Nutr 39 (2000) 53-61.

[2] Q. Zhang, Y.Q. Wang, X.Y. Meng, R. Dhar, H.D. Huang, Triple-Stranded DNA containing 8-Oxo-7,8-dihydro-2'-deoxyguanosine: Implication in the design of selective aptamer sensors for 8-Oxo-7, 8-dihydroguanine, Anal. Chem. 85 (2013) 201-207.

[3] K.C. Cheng, D.S. Cahill, H. Kasai, S. Nishimura, L.A. Loeb, 8-Hydroxyguanine, an abundant form of oxidative DNA damage, causes $\mathrm{G} \rightarrow \mathrm{T}$ and $\mathrm{A} \rightarrow \mathrm{C}$ substitutions, $\mathrm{J}$ Biol. Chem. 267 (1992) 166-72.

[4] L.L. Wu, C.C. Chiou, P.Y. Chang, J.T. Wu, Urinary 8-OHdG: a marker of oxidative stress to DNA and a risk factor for cancer, atherosclerosis and diabetics, Clin. Chim. Acta 339 (2004) 1-9.

[5] M. Kakimoto, T. Inoguchi, T. Sonta, M. Imamura, T. Etoh, T. Hashimoto, H. Nawata, Accumulation of 8-Hydroxy-2'-Deoxyguanosine and mitochondrial DNA deletion in kidney of diabetic rats, Diabetes 51 (2002) 1588-1595.

[6] A. Kikuchi, A. Takeda, H. Onodera, T. Kimpara, K. Hisanaga, N. Sato, A. Nunomura, R.J. Castellani, G. Perry, M.A. Smith, Y. Itoyama, Systemic increase of oxidative nucleic acid damage in Parkinson's disease and multiple system atrophy, Neurobiol. Dis. 9 (2002) 244-248. 
[7] M. Erhola, S. Toyokuni, K. Okada, T. Tanaka, H. Hiai, H. Ochi, K. Uchida, T. Osawa, M.M. Nieminen, H. Alho, P.K. Lehtinen, Biomarker evidence of DNA oxidation in lung cancer patients: association of urinary 8-hydroxy-2'-deoxyguanosine excretion with radiotherapy, chemotherapy, and response to treatment, FEBS Letters 409 (1997) 287-291.

[8] A. Gutiérrez, S. Osegueda, S.G.-Granados, A. Alatorre, M.G. García, L.A. Godínez, Amperometric detection and quantification of 8-Hydroxy-2'-deoxyguanosine (8-OHdG) using dendrimer modified electrodes, Electroanal. 20 (2008) 2294-2300.

[9] M.I. Churchwell, F.A. Beland, D.R. Doerge, Quantification of multiple DNA adducts formed through oxidative stress using liquid chromatography and electrospray tandem mass spectrometry, Chem. Res. Toxicol. 15 (2002) 1295-1301. [10] J.J. Hu, W.B. Zhang, H.M. Ma, Y.M. Cai, G.Y. Sheng, J.M. Fu, Simultaneous determination of 8-hydroxy-2'-deoxyguanosine and 5-methyl-2'-deoxycytidine in DNA sample by high performance liquid chromatography/positive electrospray ionization tandem mass spectrometry, J. Chromatogr. B 878 (2010) 2765-2769.

[11] B. Yin, R.M. Whyatt, F.P. Perera, M.C. Randall, T.B. Cooper, R.M. Santella, Determination of 8-hydroxydeoxyguanosine by an immunoaffinity chromatography-monoclonal antibody-based ELISA, Free Radical Biol. Med. 18 (1995) 1023-1032.

[12] R.C. Gupta, J.M. Arif, An improved ${ }^{32}$ P-postlabeling assay for the sensitive detection of 8-oxodeoxyguanosine in tissue DNA, Chem. Res. Toxicol. 14 (2001) 951-957.

[13] S.K. Srivastava, V.K. Gupta, S. Jain, PVC-Based 2,2,2-Cryptand Sensor for Zinc Ions, Anal. Chem. 68 (1996) 1272-1275.

[14] R.N. Goyal, V. K. Gupta, S. Chatterjee, Simultaneous determination of adenosine and inosine using single-wall carbon nanotubes modified pyrolytic graphite electrode, Talanta 76 (2008) 66-668.

[15] T.H. Li, W.L. Jia, H.S. Wang, R.M. Liu, Electrochemical performance of 
8-hydroxy-2'-deoxyguanosine and its detection at poly(3-methylthiophene) modified glassy carbon electrode, Biosens. Bioelectron. 22 (2007) 1245-1250.

[16] A. Gutiérrez, S. Gutiérrez, G. García, L. Galicia, G.A. Rivasc, Determinatiom of 8-hydroxy 2'-deoxyguanosine using electrodes modified with a dispersion of carbon nanotubes in polyethylenimine, Electroanal. 23 (2011) 1221-1228.

[17] Y. Dong, H. Cui, Y. Xu, Comparative studies on electrogenerated chemiluminescence of luminol on gold nanoparticle modified electrodes, Langmuir 23 (2007) 523-529.

[18] S. Xu, Y. Liu, T. Wang, J. Li, Highly sensitive electrogenerated chemiluminescence biosensor in profiling protein kinase activity and inhibition using gold nanoparticle as signal transduction probes, Anal. Chem. 82 (2010) 9566-9572.

[19] L.J. Hua, J.J. Zhou, H.Y. Han. Direct electrochemiluminescence of CdTe quantum dots based on roomtemperature ionic liquid film and high sensitivity sensing of gossypol, Electrochim. Acta 55 (2010) 1265-1271.

[20] L. Li, X.F. Hu, Y.M. Sun, X.L. Zhang, W.R. Jin, Electrochemiluminescence resonance energy transfer between quantum dots (QDs) as the donor and Cy5 dye molecules as the acceptor in QD-Cy5 conjugates with biomolecules as the linker, Electrochem. Commun. 13 (2011) 1174-1177.

[21] G.F. Jien, Y.B. Zhao, S.Y. Niu, Amplified electrochemiluminescence detection of cancer cells using a new bifunctional quantum dot as signal probe, Biosens. Bioelectron. 50 (2013) 368-372.

[22] N. Gaponik, D.V. Talapin, A.L. Rogach, K. Hoppe, E.V. Shevchenko, A. Kornowski, A. Eychmulller, H. Weller, Thiol-capping of CdTe nanocrystals: an alternative to organometallic synthetic routes, J. Phys. Chem. B 106 (2002) 7177-7185.

[23] Y.P. Sun, B. Zhou, Y. Lin, W. Wang, K.A. Shiral Fernando, P. Pathaket, M.J. Meziani, B.A. Harruff, X. Wang, H.F. Wang, P.G. Luo, H. Yang, M.E. Kose, B. Chen, L.M. Veca, S.Y. Xie, Quantum-sized carbon dots for bright and colorful photoluminescence, J. Am. Chem. Soc. 128 (2006) 7756-7757. 
[24] Q.L. Zhao, Z.L. Zhang, B.H. Huang, J. Peng, M. Zhang, D.W. Pang, Facile preparation of low cytotoxicity fluorescent carbon nanocrystals by electrooxidation of graphite, Chem. Commun. 41 (2008) 5116-5118.

[25] X.J. Mao, H.Z. Zheng, Y.J. Long, J. Du, J.Y. Hao, L.L. Wang, D.B. Zhou, Study on the fluorescence characteristics of carbon dots, Spectrochim Acta A Mol. Biomol. Spectrosc. 75 (2010) 553-557.

[26] H.T. Li, Z.H. Kang, Y. Liu, S.T. Lee, Carbon nanodots: synthesis, properties and applications, J. Mater. Chem. 22 (2012) 24230-24253.

[27] Y.P. Sun, X. Wang, F.S. Lu, L. Cao, M.J. Meziani, P.J.G. Luo, L.R. Gu, L.M. Veca, Doped carbon nanoparticles as a new platform for highly photoluminescent dots, J. Phys. Chem. C 112 (2008) 18295-18298.

[28] N.G. Liu, B.S. Prall, V.I. Klimov, Hybrid gold/silica/nanocrystal-quantum-dot superstructures: synthesis and analysis of semiconductor-metal interactions, J. Am. Chem. Soc. 128 (2006) 15362-15363.

[29] B. Zhang, C.Y. Liu, Y. Liu, A novel one-step approach to synthesize fluorescent carbon nanoparticles, Eur. J. Inorg. Chem. 28 (2010) 4411-4414.

[30] N.G. Bastús, J. Comenge, V. Puntes, Kinetically controlled seeded growth synthesis of citrate-stabilized gold nanoparticles of up to $200 \mathrm{~nm}$ : size focusing versus ostwald ripening, Langmuir 27 (2011) 11098-11105.

[31] Y.F. Huang, K.H. Ma, K.B. Kang, M. Zhao, Z.L. Zhang, Y.X. Liu, T. Wen, Q. Wang, W.Y. Qiu, D. Qiu, Core-shell plasmonic nanostructures to fine-tune long “Au nanoparticle-fluorophore" distance and radiative dynamics, Colloids and Surfaces A: Physicochem. Eng. Aspects 421 (2013) 101-108.

[32] K. Yang, S. Zhang, G. Zhang, X. Sun, S.T. Lee, Z. Liu, Graphene in mice: ultrahigh in vivo tumor uptake and efficient photothermal therapy, Nano Lett. 10 (2010) 3318-3323.

[33] R.L. Liu, D.Q. Wu, S.H. Liu, K. Koynov, W. Knoll, Q. Li, An aqueous route to multicolor photoluminescent carbon dots using silica spheres as carriers, Angew. Chem. Int. Ed. 48 (2009) 4598-4601. 
[34] Y.F. Cheng, R. Yuan, Y.Q. Chai, H. Niu, Y.L. Cao, H.J. Liu, L.J. Bai, Y.L. Yuan, Highly sensitive luminol electrochemiluminescence immunosensor based on $\mathrm{ZnO}$ nanoparticles and glucose oxidase decorated graphene for cancer biomarker detection, Ana. Chim. Acta 745 (2012) 137-142.

[35] R. Yuan, D.P. Tang, Y.Q. Chai, X. Zhong, Y. Liu, J.Y. Dai, Ultrasensitive potentio-metric immunosensor based on SA and OCA techniques for immobilization of HBsAb with colloidal Au and polyvinyl butyral as matrixes, Langmuir 20 (2004) 7240-7245.

[36] P.M.W. Lam, V. Mistry, T.H. Marczylo, J.C. Konje, M.D. Evans, M.S. Cooke, Rapid measurement of 8-oxo-7, 8-dihydro-2'-deoxyguanosine in human biological matrices using ultra-high-performance liquid chromatography-tandem mass spectrometry, Free Radical Bio. Med. 52 (2012) 2057-2063. 


\section{Figure captions}

Scheme 1. Chemical structure of 8-OHdG.

Scheme 2. Schematic illustration of the preparation procedure of $\mathrm{Au} / \mathrm{SiO}_{2} / \mathrm{CQDs}$ core-shell nanoparticles.

Scheme 3. Schematic illustration of the preparation processes of the ECL electrode modified by $\mathrm{Au} / \mathrm{SiO}_{2} / \mathrm{CQDs}$ core-shell nanoparticles and antibody.

Scheme 4. Schematic illustration of the detection procedures of the ECL immunosensor.

Fig. 1. Photoluminescence emission spectra (the left coordinates) and UV/Vis absorption spectra (Abs) (the right coordinates) of the CQDs, excitation wavelength: (a) $300 \mathrm{~nm}$, (b) $320 \mathrm{~nm}$, (c) $340 \mathrm{~nm}$, (d) $360 \mathrm{~nm}$, (e) $380 \mathrm{~nm}$, (f) $400 \mathrm{~nm}$, (g) $420 \mathrm{~nm}$.

Fig. 2. (A) TEM images of $\mathrm{Au} / \mathrm{SiO}_{2} / \mathrm{CQDs}$ core-shell nanoparticles (inset: AuNPs). (B) EDS of $\mathrm{Au} / \mathrm{SiO}_{2} / \mathrm{CQDs}$ core-shell nanoparticles (inset: SEM images).

Fig. 3. The ECL signals of (a) bare Pt electrode, (b) Pt/CQDs, (c) $\mathrm{Pt} / \mathrm{Au} / \mathrm{SiO}_{2} / \mathrm{CQDs} / \mathrm{Ab}, \quad$ (d) $\quad \mathrm{Pt} / \mathrm{Au} / \mathrm{SiO}_{2} / \mathrm{CQDs} / \mathrm{Ab} / \mathrm{BSA}$,

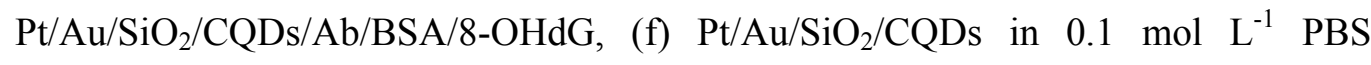
solution (pH 7.4) containing $0.1 \mathrm{~mol} \mathrm{~L}^{-1} \mathrm{KCl}$ and $0.05 \mathrm{~mol} \mathrm{~L}^{-1} \mathrm{~K}_{2} \mathrm{~S}_{2} \mathrm{O}_{8}$. Scan rate, $0.01 \mathrm{~V} \mathrm{~s}^{-1}$. The voltage of PMT was $600 \mathrm{~V}$.

Fig. 4. (A) Effects of $\mathrm{pH}$ value of $\mathrm{PBS}$ solution and (B) incubation time of 8-OHdG on the response of ECL immunosensor for the detection of $100 \mathrm{ng} \mathrm{mL}^{-1} 8-\mathrm{OHdG}(\mathrm{n}=$ $3)$.

Fig. 5. (A) ECL responses of the proposed ECL immunosensor to different concentrations of $8-\mathrm{OHdG}\left(0,0.2,0.5,1,5,10,25,50,100,150\right.$ and $\left.200 \mathrm{ng} \mathrm{mL}^{-1}\right)$ in $0.1 \mathrm{~mol} \mathrm{~L}^{-1}$ PBS solution ( $\mathrm{pH} 7.4$ ) containing $0.1 \mathrm{~mol} \mathrm{~L}^{-1} \mathrm{KCl}$ and $0.05 \mathrm{~mol} \mathrm{~L}^{-1}$ $\mathrm{K}_{2} \mathrm{~S}_{2} \mathrm{O}_{8}$. Scan rate, $0.01 \mathrm{~V} \mathrm{~s}^{-1}$. The voltage of PMT was $600 \mathrm{~V}$. (B) The calibration curve for 8-OHdG assay $(n=3)$.

Fig. 6. ECL responses of the proposed ECL immunosensor of 8-OHdG, uric acid, ascorbic acid, and guanine at concentration of $100 \mathrm{ng} \mathrm{mL}^{-1}$, respectively $(\mathrm{n}=3)$. All measurements were performed in $0.1 \mathrm{~mol} \mathrm{~L}^{-1} \mathrm{PBS}$ solution ( $\mathrm{pH} 7.4$ ) containing 0.1 
mol L $\mathrm{KCl}^{-1}$ and $0.05 \mathrm{~mol} \mathrm{~L}^{-1} \mathrm{~K}_{2} \mathrm{~S}_{2} \mathrm{O}_{8}$. Scan rate, $0.01 \mathrm{~V} \mathrm{~s}^{-1}$. The voltage of PMT was $600 \mathrm{~V}$.

Fig. 7. The ECL intensities of sixteen consecutive cycles of the proposed ECL immunosensor incubated with $100 \mathrm{ng} \mathrm{mL} \mathrm{m}^{-1} 8-\mathrm{OHdG}$ in $0.1 \mathrm{~mol} \mathrm{~L}^{-1}$ PBS solution (pH 7.4) containing $0.1 \mathrm{~mol} \mathrm{~L}^{-1} \mathrm{KCl}$ and $0.05 \mathrm{~mol} \mathrm{~L}^{-1} \mathrm{~K}_{2} \mathrm{~S}_{2} \mathrm{O}_{8}$. Scan rate, $0.01 \mathrm{~V} \mathrm{~s}^{-1}$. The voltage of PMT was $600 \mathrm{~V}$. 
Table 1 The atomic ratios of $\mathrm{Au} / \mathrm{SiO}_{2} / \mathrm{CQD}$ s core-shell nanoparticles.

\begin{tabular}{ccc}
\hline Element & Intensity $(\mathrm{c} / \mathrm{s})$ & $\mathrm{Wt} \%$ \\
\hline $\mathrm{C}$ & 24.46 & 15.333 \\
$\mathrm{O}$ & 75.52 & 25.461 \\
$\mathrm{Si}$ & 281.10 & 27.795 \\
$\mathrm{Au}$ & 213.85 & 31.412 \\
\hline
\end{tabular}


Table 2 Comparison between the described ECL immune method and referenced methods for 8-OHdG detection.

\begin{tabular}{cccc}
\hline Detection method & Linear range $\left(\mathrm{ng} \mathrm{mL}^{-1}\right)$ & Detection limit $\left(\mathrm{ng} \mathrm{mL}^{-1}\right)$ & References \\
\hline DNA aptamer sensor & $0.849-283$ & - & {$[2]$} \\
HPLC-ECD & - & 0.34 & {$[8]$} \\
Electrochemical & $198.1-9905$ & 28.3 & {$[13]$} \\
Electrochemical & $9905-19800$ & 28.3 & {$[14]$} \\
ECL immune method & $141.5-8490$ & 0.085 & This paper \\
\hline
\end{tabular}


Table 3 Determination of $8-\mathrm{OHdG}$ in milk and recoveries of the samples with different concentrations of 8-OHdG.

\begin{tabular}{ccccc}
\hline $\begin{array}{c}\text { Sample } \\
\text { namble }\end{array}$ & $\begin{array}{c}\text { Added } \\
\left(\mathrm{ng} \mathrm{mL}^{-1}\right)\end{array}$ & $\begin{array}{c}\text { Measured } \pm \text { SD } \\
\left(\mathrm{ng} \mathrm{mL}^{-1}\right)\end{array}$ & $\begin{array}{c}\text { Recovery } \\
(\%)\end{array}$ & $\begin{array}{c}\text { RSD } \\
(\%, \mathrm{n}=3)\end{array}$ \\
\hline 1 & 0.5 & $0.51 \pm 0.02$ & 102.0 & 5.2 \\
2 & 1 & $1.11 \pm 0.08$ & 110.0 & 7.6 \\
3 & 10 & $10.68 \pm 0.82$ & 107.0 & 7.7 \\
4 & 50 & $51.60 \pm 2.52$ & 103.2 & 4.9 \\
5 & 100 & $103.10 \pm 5.99$ & 103.1 & 5.8 \\
\hline
\end{tabular}




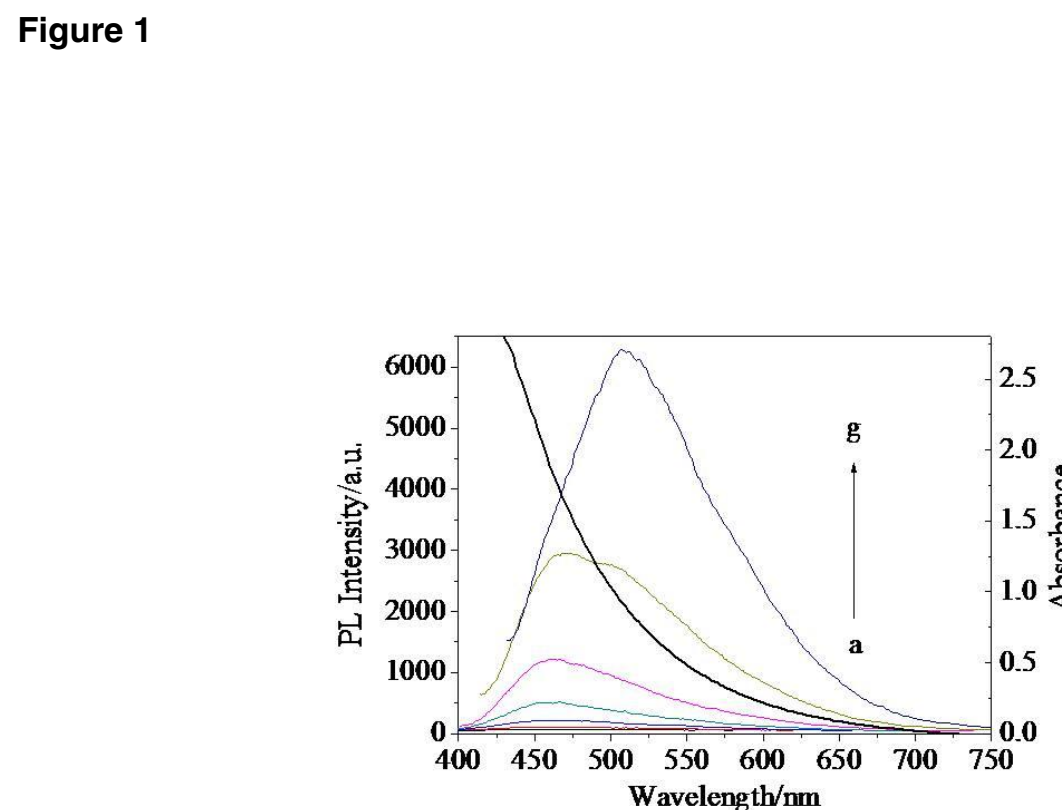

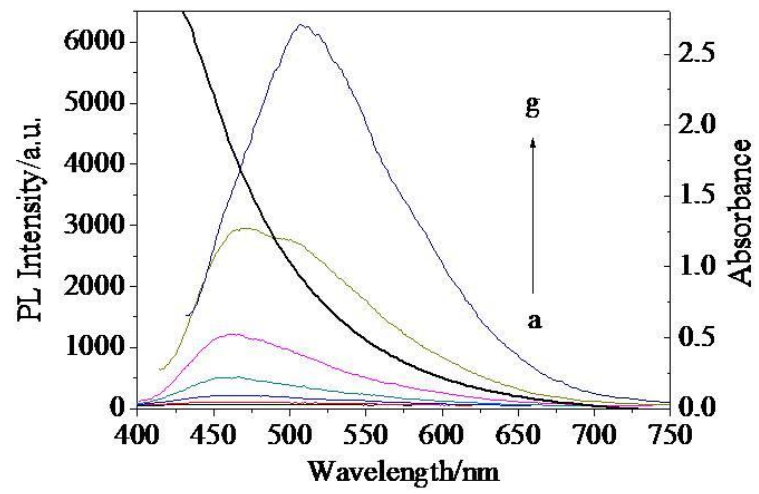

总

5

. 

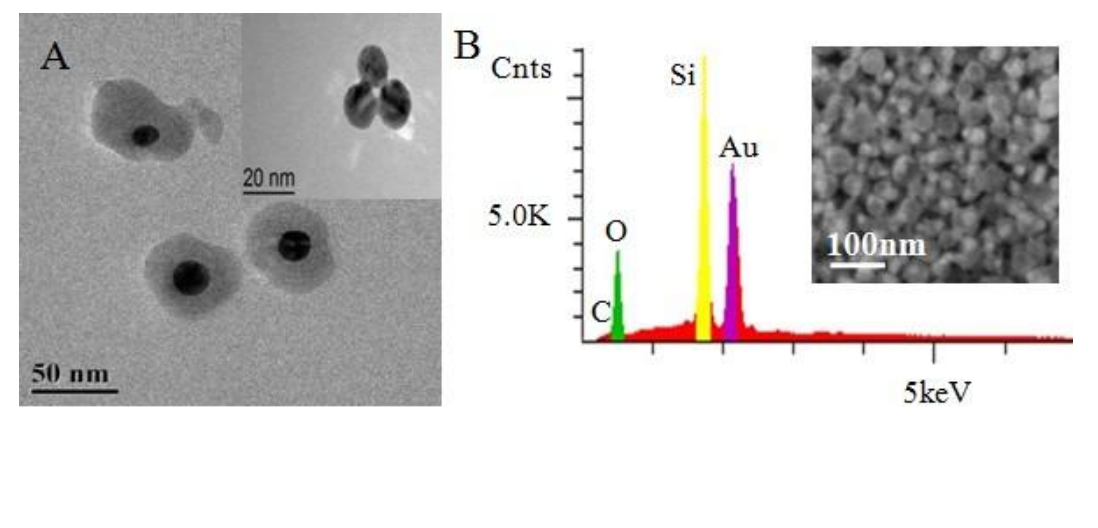

Figure 2

$50 \mathrm{~nm}$

$\therefore \mathrm{A}^{\circ} \mathrm{L}$

.

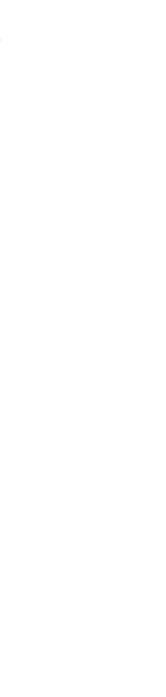




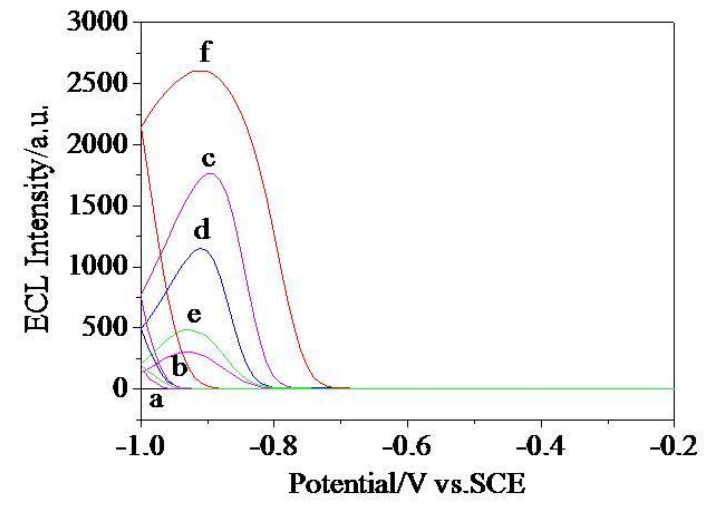


Figure 4
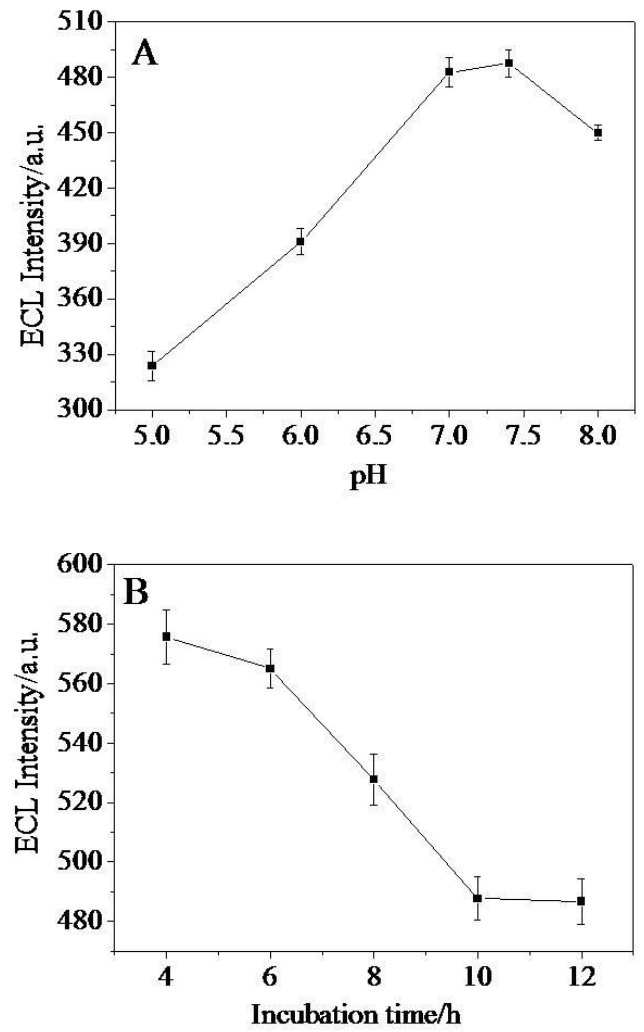
Figure 5
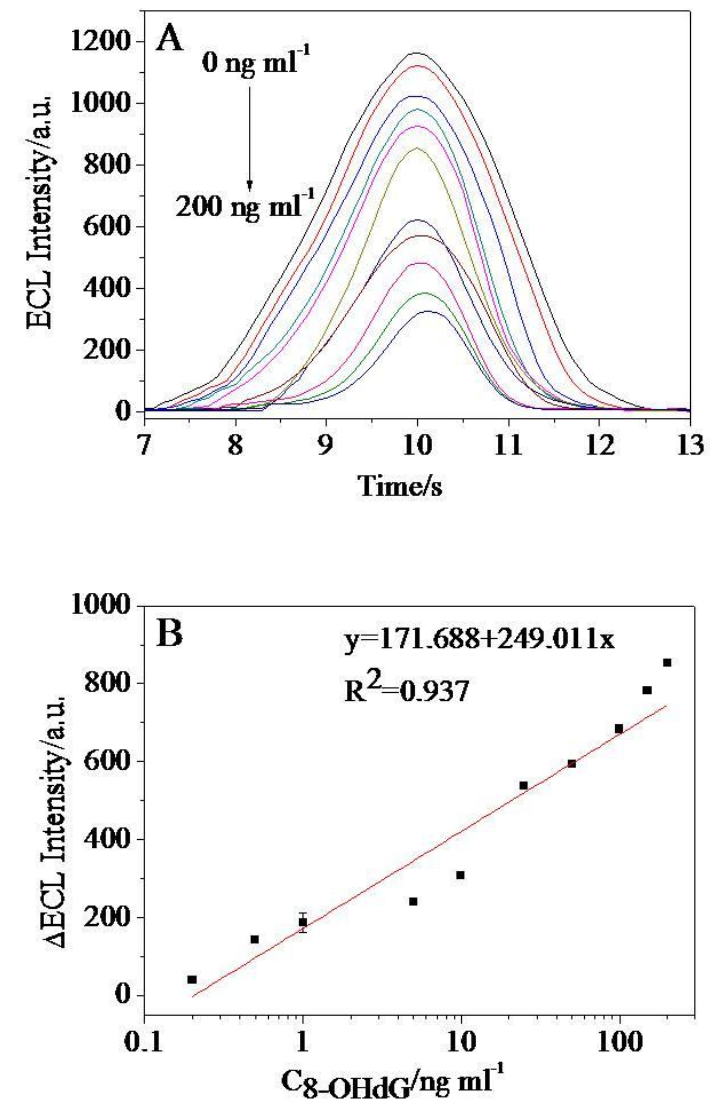
Figure 7

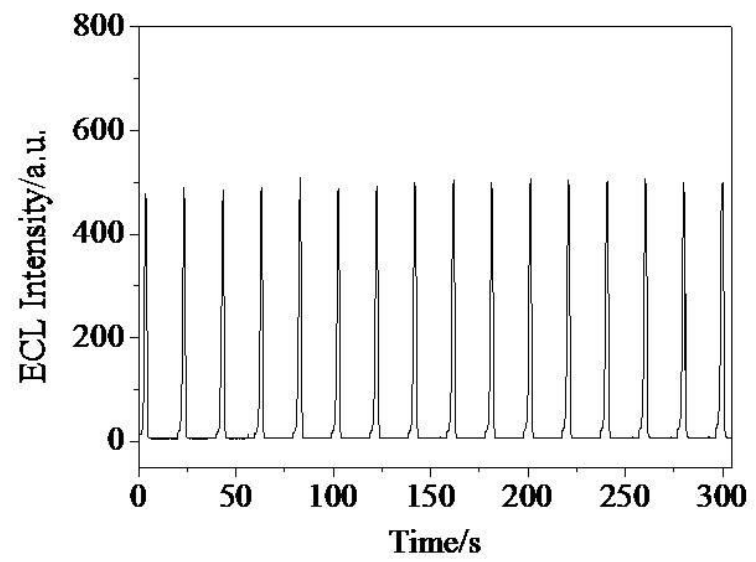


<smiles>Nc1nc2c([nH]c(=O)n2[C@H]2C[C@H](O)[C@@H](CO)O2)c(=O)[nH]1</smiles> 

scheme 2

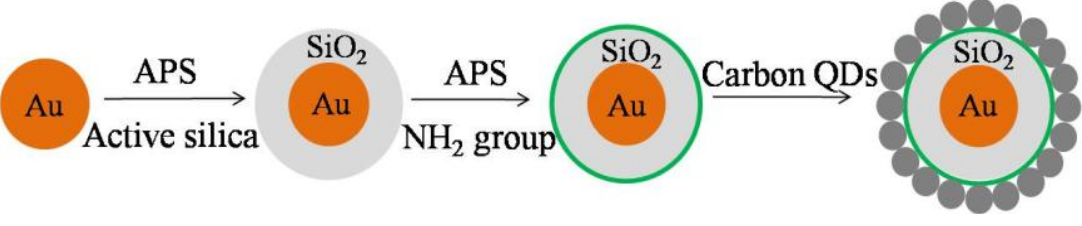

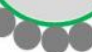




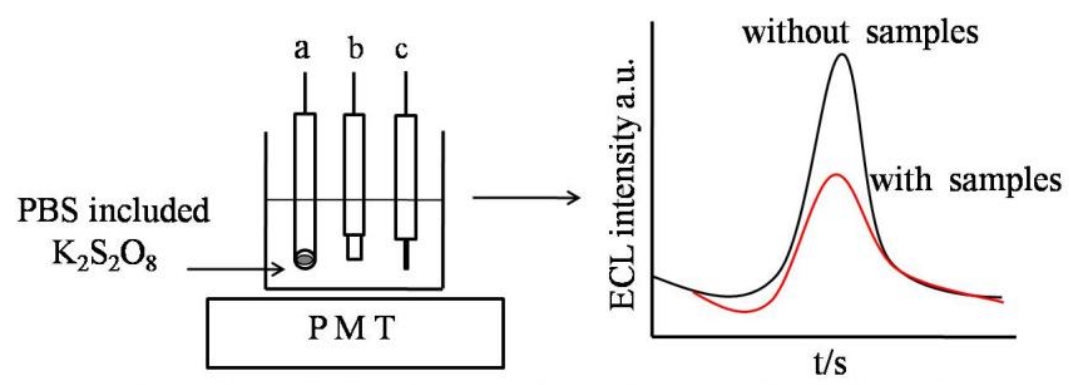

a: working electrode, b: reference electrode, c: auxiliary electrode 


\section{A table of contents entry}

A rapid, and highly sensitive electrochemiluminescence immunosensor based on carbon quantum dot coated $\mathrm{Au} / \mathrm{SiO}_{2}$ core-shell nanoparticles is presented for 8-hydroxy-2'-deoxyguanosine detection.
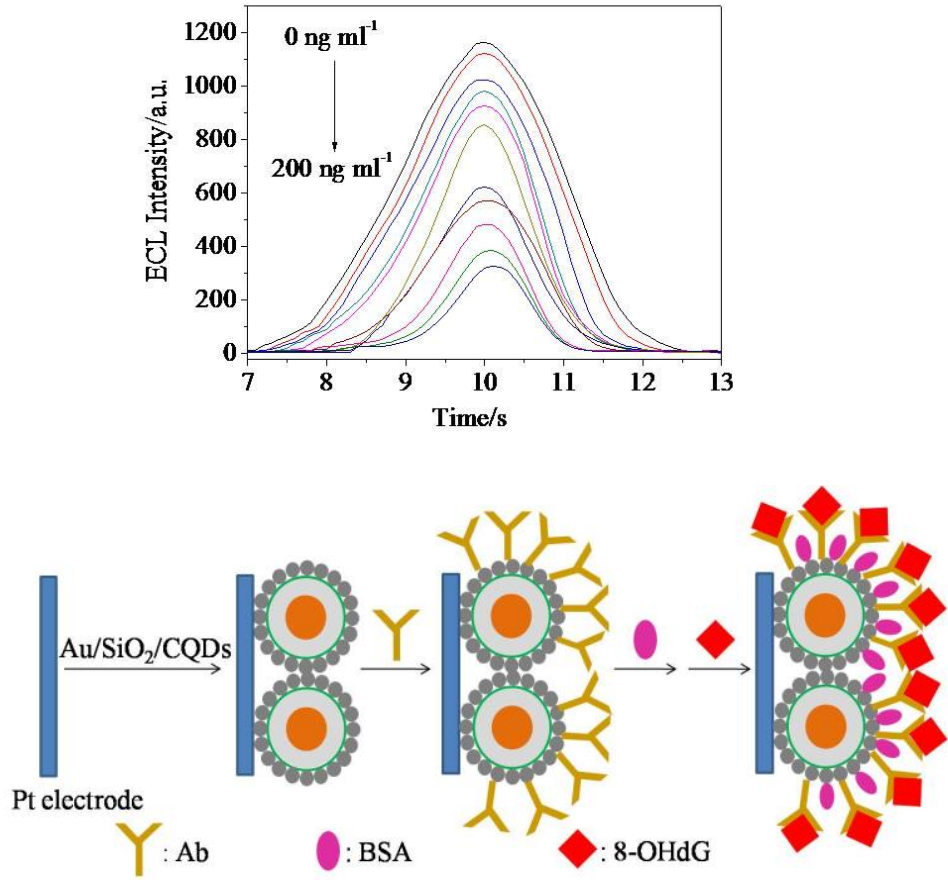